\title{
Differing Activity Profiles of the Stereoisomers of 2,3,5,6TMP-TQS, a Putative Silent Allosteric Modulator of $\alpha 7$ nAChR
}

\author{
Roger L. Papke, Sumanta Garai, Clare Stokes, Nicole A. Horenstein, Arthur D. Zimmerman, \\ Khalil A. Abboud, and Ganesh A. Thakur
}

Departments of Pharmacology and Therapeutics (R.L.P., C.S., A.D.Z.) and Chemistry (N.A.H., K.A.A.), University of Florida, Gainesville, Florida; and Department of Pharmaceutical Sciences, School of Pharmacy, Bouvé College of Health Sciences, Northeastern University, Boston, Massachusetts (S.G., G.A.T.)

Received March 3, 2020; accepted July 13, 2020

\begin{abstract}
Many synthetic compounds to which we attribute specific activities are produced as racemic mixtures of stereoisomers, and it may be that all the desired activity comes from a single enantiomer. We have previously shown this to be the case with the $\alpha 7$ nicotinic acetylcholine receptor positive allosteric modulator (PAM) 3a,4,5,9b-Tetrahydro-4-(1-naphthalenyl)-3H-cyclopentan[c]quinoline-8-sulfonamide (TQS) and the $\alpha 7$ ago-PAM 4BP-TQS. Cis-trans-4-(2,3,5,6-tetramethylphenyl)-3a,4,5,9b-tetrahydro-3H-cyclopenta[c]quinoline-8-sulfonamide (2,3,5,6TMPTQS), previously published as a "silent allosteric modulator" and an antagonist of $\alpha 7$ allosteric activation, shares the same scaffold with three chiral centers as the aforementioned compounds. We isolated the enantiomers of 2,3,5,6TMP-TQS and determined that the $(-)$ isomer was a significantly better antagonist than the $(+)$ isomer of the allosteric activation of both wild-type $\alpha 7$ and the nonorthosterically activatible C190A $\alpha 7$ mutant by the ago-PAM GAT107 (the active isomer of 4BP-TQS). In contrast, (+)2,3,5,6TMPTQS proved to be an $\alpha 7$ PAM. (-)2,3,5,6TMP-TQS was shown to antagonize the allosteric activation of $\alpha 7$ by the structurally unrelated ago-PAM B-973B as well as the allosteric activation of the TQS-sensitive $\alpha 4 \beta 2 \mathrm{~L} 15^{\prime} \mathrm{M}$ mutant. In silico docking of
\end{abstract}

$2,3,5,6$ TMP-TQS in the putative allosteric activation binding site suggested a specific interaction of the $(-)$ enantiomer with $\alpha 7$ T106, and allosteric activation of $\alpha 7$ T106 mutants was not inhibited by $(-) 2,3,5,6 \mathrm{TMP}-\mathrm{TQS}$, confirming the importance of this interaction and supporting the model of the allosteric binding site. Comparisons and contrasts between 2,3,5,6TMP-TQS isomers and active and inactive enantiomers of other TQS-related compounds identify the orientation of the cyclopentenyl ring to the plane of the core quinoline to be a crucial determinate of PAM activity.

\section{SIGNIFICANCE STATEMENT}

Many synthetic ligands are in use as racemic preparations. We show that one enantiomer of the TQS analog Cis-trans4-(2,3,5,6-tetramethylphenyl)-3a,4,5,9b-te-trahydro-3H-cyclopenta[c]quinoline-8-sulfonamide, originally reported to lack activity when used as a racemic preparation, is an $\alpha 7$ nicotinic acetylcholine receptor positive allosteric modulator (PAM). The other enantiomer is not a PAM, but it is an effective allosteric antagonist. In silico studies and structural comparisons identify essential elements of both the allosteric ligands and receptor binding sites important for these allosteric activities.

\section{Introduction}

Nicotinic acetylcholine receptors $(\mathrm{nAChR})$ are pentameric assemblies of subunits that function as ligand-gated ion channels (Papke, 2014). In the peripheral nervous system, heteromeric $\mathrm{nAChR}$ mediate synaptic transmission at neuromuscular

This research was supported by National Institutes of Health National Institute of General Medical Sciences [Grant R01-GM57481] (to R.L.P., C.S., N.A.H.) and National Institutes of Health National Eye Institute [Grant R01EY024717] (to S.G., G.A.T.).

https://doi.org/10.1124/mol.120.119958.

S This article has supplemental material available at molpharm. aspetjournals.org. junctions and autonomic ganglia. In the brain, heteromeric $\mathrm{nAChR}$ mediate both cognitive effects of $\mathrm{ACh}$ and addictive effects of nicotine. A third class of $\mathrm{nAChR}$ are those that can form functional receptors as homopentamers, and the best studied of these are composed of $\alpha 7$ subunits. Several features distinguish homomeric $\alpha 7$ receptors from heteromeric $\mathrm{nAChR}$. Although all $\mathrm{nAChR}$ subtypes desensitize in the continued presence of agonist, the desensitization of $\alpha 7 \mathrm{nAChR}$ to high concentrations of agonist is especially rapid but also readily reversible. As a consequence of $\alpha 7$ 's unique mode of desensitization, $\alpha 7$ receptors have an intrinsically low probability of channel activation (Williams et al., 2012).

ABBREVIATIONS: 2,3,5,6TMP-TQS, Cis-trans-4-(2,3,5,6-tetramethylphenyl)-3a,4,5,9b-te-trahydro-3H-cyclopenta[c]quinoline-8-sulfonamide; 2,4,MPTQS, cis-cis-4-(2,4-dimethylphenyl)-3a,4,5,9b-tetrahydro-3H-cyclopenta[c]quinoline-8-sulfonamide; AA site, allosteric activation binding site; ACh, acetylcholine; B-973B, (S)-3-(3,4-difluorophenyl)-N-(1-(6-(4-(pyridin-2-yl)piperazin-1-yl)pyrazin-2-yl)ethyl)propanamide; Cl, confidence interval; GAT107, (3aR,4S,9bS)-4-(4-bromophenyl)-3a,4,5,9b-tetrahydro-3H-cyclopenta[c]quinoline-8-sulfonamide; GAT927, 4-(4,5,6,7-tetrahydrobenzo[b]thiophen-3-yl)3a,4,5,9b-tetrahydro-3H-cyclopenta[c]quinoline-8-sulfonamide; nAChR, nicotinic acetylcholine receptor; PAM, positive allosteric modulator; TQS, 3a,4,5,9b-Tetrahydro-4-(1-naphthalenyl)-3H-cyclopentan[c]quinoline-8-sulfonamide. 
All nAChR are allosteric proteins, such that their functional properties are regulated by sites other than the orthosteric sites where typical agonists bind (Changeux, 1981; Bertrand and Gopalakrishnan, 2007; Williams et al., 2011). Some of the most profound effects of allosteric ligands have been described for $\alpha 7 \mathrm{nAChR}$, and some positive allosteric modulators (PAMS) reverse intrinsic limitations on channel activation (Williams et al., 2012). The binding site for $\alpha 7$ PAMs is within the receptor's transmembrane domains (Young et al., 2008) and requires the presence of a methionine residue that is unique to $\alpha 7$ in the pore-forming second transmembrane domain (Stokes et al., 2019).

One large class of PAMs is based on TQS, a sulfonamidecontaining multiring molecule (Gronlien et al., 2007; Gill et al., 2012). In addition to acting as a PAM, one analog, 4BPTQS, produces direct allosteric activation of $\alpha 7$ receptors as well as long-lived potentiation of orthosteric agonist responses, identifying the compound as an "ago-PAM." GAT107 is the active isomer of 4BP-TQS (Papke et al., 2014), and both allosteric activation and positive modulation of $\alpha 7$ by GAT107 require the specific sequence in the $\alpha 7$ transmembrane domains. Although it was initially hypothesized that this sequence alone was sufficient for allosteric activation (Gill et al., 2011), we have provided evidence for a second allosteric activation binding site (AA site) in the receptor's extracellular domain (Papke et al., 2014; Horenstein et al., 2016; Gulsevin et al., 2019).

Cis-trans-4-(2,3,5,6-tetramethylphenyl)-3a,4,5,9b-tetrahydro-3H-cyclopenta[c] quinoline-8-sulfonamide (2,3,5,6TMP-TQS) was previously identified as a "silent allosteric modulator" of $\alpha 7$ nAChR (Gill-Thind et al., 2015) based on its apparent lack of positive or negative effect on activation by $100 \mu \mathrm{M}$ of ACh. Although apparently silent in regard to activation by $100 \mu \mathrm{M}$ ACh, 2,3,5,6TMP-TQS blocked allosteric activation of $\alpha 7$ by the ago-PAM 2,4,MP-TQS. Subsequently, we used $2,3,5,6 \mathrm{TMP}-\mathrm{TQS}$ [previously identified as 2,3,5,6MP-TQS (Gill-Thind et al., 2015)] as a tool to characterize the allosteric agonist activity of GAT107 (Thakur et al., 2013; Papke et al., 2014).

The allosteric activation of $\alpha 7$ produced by an application of GAT107 persists only as long as the drug is free in solution. Repeated applications of GAT107 produce additional episodes of allosteric activation, suggesting that there is rapid binding and dissociation of GAT107 at the AA site. In contrast to the rapid transient effects of GAT107 as an allosteric agonist, after a single application of GAT107, subsequent applications of ACh alone are increased in amplitude and duration. This "primed potentiation" can persist for at least an hour (Papke et al., 2018). We have observed that the coapplication of GAT107 with 2,3,5,6TMP-TQS could specifically reduce direct allosteric activation without apparent effects on primed potentiation, suggesting that 2,3,5,6TMP-TQS is a selective antagonist of the extracellular AA site with little or no effect at the transmembrane site required for allosteric potentiation.

Although allosteric activation by GAT107 does require positive allosteric modulation at the transmembrane PAM binding site, it does not require a functional binding site for orthosteric agonists (Horenstein et al., 2016). We recently

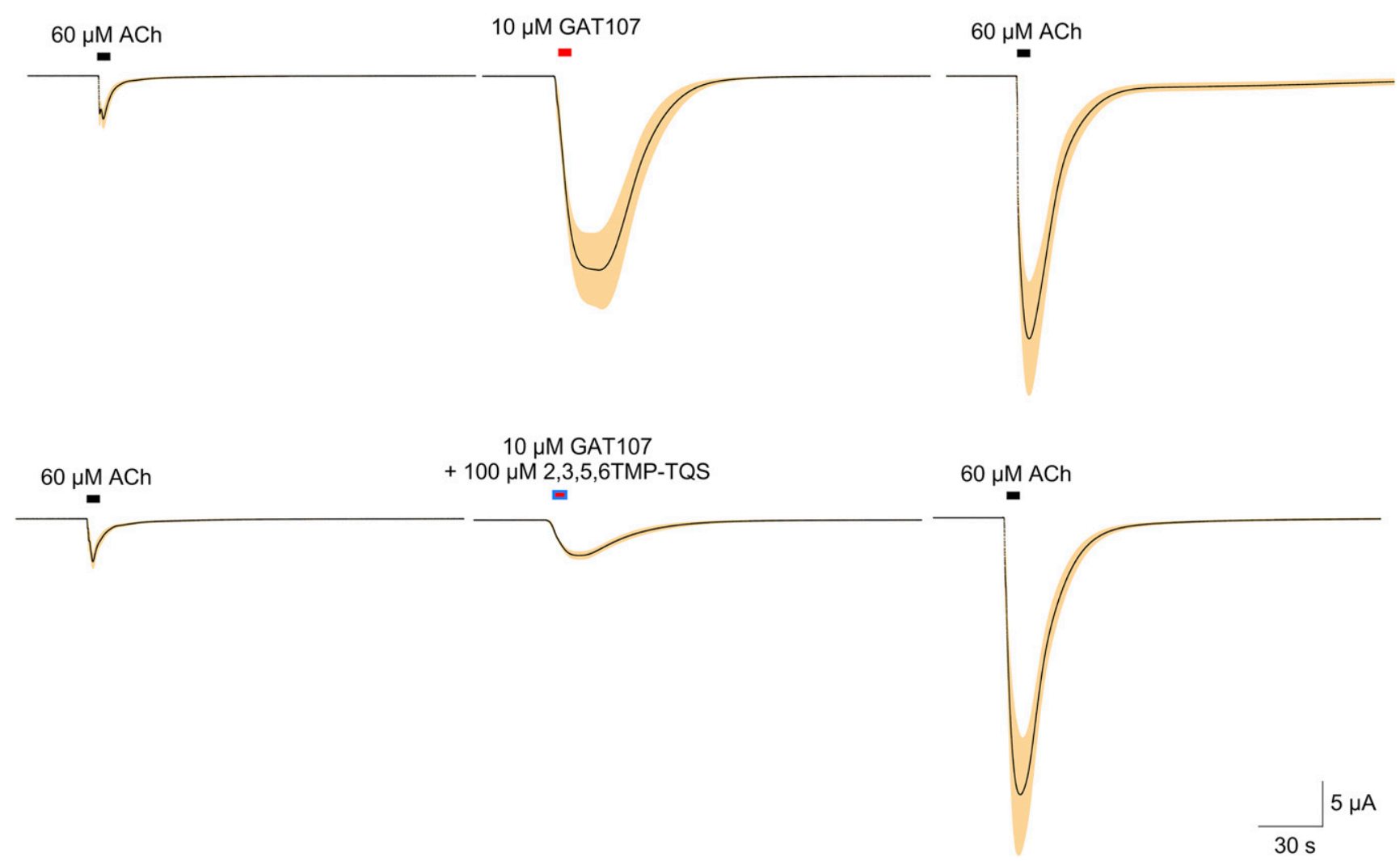

Fig. 1. Coapplication of $100 \mu \mathrm{M}$ racemic 2,3,5,6TMP-TQS selectively inhibits the direct allosteric activation of $\alpha 7 \mathrm{nAChR}$ by $10 \mu \mathrm{M}$ of the ago-PAM GAT107 $(P<0.00001)$ with no effect on subsequent potentiation of responses to ACh. Averaged raw data traces for cells (see Materials and Methods) were normalized to the control responses to $60 \mu \mathrm{M}$ ACh shown. The S.E.M. of the averaged normalized responses are represented by the tan colored areas. 


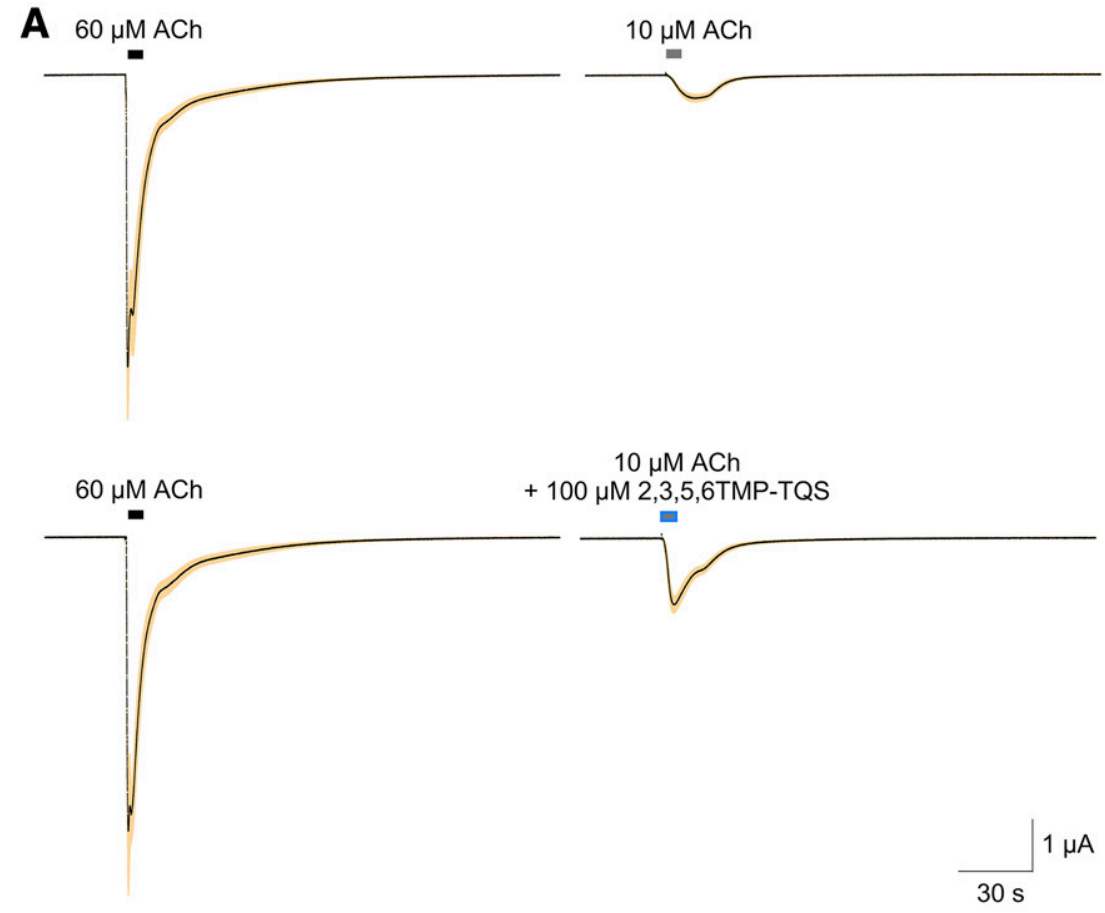

Fig. 2. Coapplication of racemic $100 \mu \mathrm{M}$ 2,3,5,6TMPTQS potentiates $\alpha 7 \mathrm{nAChR}$ responses to a low $(10 \mu \mathrm{M})$ concentration of ACh. (A) Averaged raw data traces for cells responding to $10 \mu \mathrm{M}$ ACh alone or coapplied with $100 \mu \mathrm{M}$ racemic 2,3,5,6TMP-TQS ( $n=8$ cells for each condition). Data were normalized to the control responses to $60 \mu \mathrm{M}$ ACh shown, and the normalized peak current amplitudes were compared with a $t$ test $(P<0.001$ ) (see Materials and Methods). The S.E.M. of the averaged normalized responses are represented by the tan colored areas. (B) Superimposed responses to $10 \mu \mathrm{M}$ ACh in (A), normalized to $60 \mu \mathrm{M}$ ACh controls. The data in blue are those obtained with coapplication of $100 \mu \mathrm{M}$

B

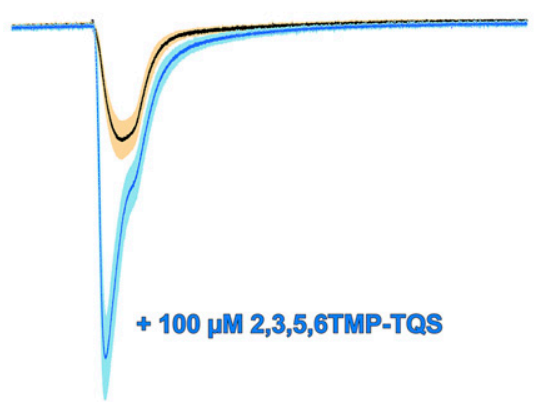

identified ligands previously classified as silent agonists that produce PAM-dependent activation of $\alpha 7$ by binding to the same AA site as GAT107 (Gulsevin et al., 2019). Racemic 2,3,5,6TMP-TQS blocks this activity, but during our experiments, we also noted that 2,3,5,6TMP-TQS could additionally potentiate the responses to low concentrations of $\mathrm{ACh}$, contrary to initial reports. Because we have previously documented large differences in the activity profiles of the stereoisomers of 4BP-TQS and TQS (Stokes et al., 2019), we hypothesized that the two stereoisomers of $2,3,5,6 \mathrm{TMP}-\mathrm{TQS}$ might discriminate between the AA and PAM binding sites. Our results confirm that only (+)2,3,5,6TMP-TQS is a PAM and that although $(-) 2,3,5,6 \mathrm{TMP}-\mathrm{TQS}$ is not a PAM, it is a more potent allosteric antagonist than (+)2,3,5,6TMP-TQS.

\section{Materials and Methods}

Chemicals and Reagents. Acetylcholine chloride (ACh) and buffer chemicals were purchased from Sigma-Aldrich Chemical Company (St. Louis, MO). GAT107 and racemic 2,3,5,6TMP-TQS were synthesized in Thakur laboratory by Dr. Sumanta Garai (Northeastern University, Boston, MA), following the published procedures (Kulkarni and Thakur, 2013; Thakur et al., 2013; GillThind et al., 2015). PNU-120596 was synthesized in the Horenstein

laboratory by Dr. Kinga Chojnacka following the published procedure (Hurst et al., 2005)

The 2,3,5,6TMP-TQS isomers were synthesized and isolated as described in the Supplemental Data.

Expression in Xenopus Oocytes. The human $\alpha 7 \mathrm{nAChR}$ clone was obtained from Dr. J. Lindstrom (University of Pennsylvania, Philadelphia, PA). The human resistance-to-cholinesterase 3 clone was obtained from Dr. M. Treinin (Hebrew University, Jerusalem, Israel) and coinjected with $\alpha 7$ to improve the level and speed of $\alpha 7$ receptor expression without affecting the pharmacological properties of the receptors (Halevi et al., 2003). After linearization and purification of the plasmid cDNAs, RNAs were prepared using the mMessage mMachine in vitro RNA transcription kit (Ambion, Austin, TX). The $\alpha 7 \mathrm{C} 190 \mathrm{~A}$ mutant was made as previously described with a $\mathrm{C} 116 \mathrm{~S}$ double mutation to prevent spurious disulfide bond formation with the free cysteine (Papke et al., 2011). The $\beta 2 \mathrm{~L} 15^{\prime} \mathrm{M}$ mutant was prepared as previously described (Stokes et al., 2019) and coexpressed with a $\beta 2-\alpha 4$ concatamer (Zhou et al., 2003) to obtain receptors with a single mutant $\beta$ subunit in the accessory subunit position outside the ACh binding sites.

Oocytes were surgically removed from mature female Xenopus laevis frogs (Nasco, Ft. Atkinson, WI). Frogs were maintained in the Animal Care Service facility of the University of Florida, and all procedures were approved by the University of Florida Institutional Animal Care and Use Committee. In brief, the frog was first anesthetized for 15-20 minutes in $1.5 \mathrm{l}$ frog tank water containing 
$1 \mathrm{~g}$ of Ethyl 3-aminobenzoate methanesulfonate buffered with sodium bicarbonate. The harvested oocytes were treated with $1.4 \mathrm{mg} / \mathrm{ml}$ Type 1 collagenase (Worthington Biochemicals, Freehold, NJ) for 2-4 hours at room temperature in calcium-free Barth's solution $(88 \mathrm{mM} \mathrm{NaCl}$, $1 \mathrm{mM} \mathrm{KCl}, 2.38 \mathrm{mM} \mathrm{NaHCO}_{3}, 0.82 \mathrm{mM} \mathrm{MgSO}_{4}, 15 \mathrm{mM}$ HEPES, and $12 \mathrm{mg} / \mathrm{l}$ tetracycline, $\mathrm{pH}$ 7.6) to remove the ovarian tissue and the follicular layers. Stage V oocytes were subsequently isolated and injected with $50 \mathrm{nl}$ of 5-20 ng nAChR subunit RNA. Oocytes were maintained in Barth's solution with calcium [additional $0.32 \mathrm{mM}$ $\mathrm{Ca}\left(\mathrm{NO}_{3}\right)_{2}$ and $0.41 \mathrm{mM} \mathrm{CaCl}$ ], and recordings were carried out 1-14 days after injection.

Two-Electrode Voltage Clamp Electrophysiology. Experiments were conducted using OpusXpress 6000A (Molecular Devices, Union City, CA) (Papke and Stokes, 2010). Both the voltage and current electrodes were filled with $3 \mathrm{M} \mathrm{KCl}$. Oocytes were voltageclamped at $-60 \mathrm{mV}$ at room temperature $\left(24^{\circ} \mathrm{C}\right)$. The oocytes were bath-perfused with Ringer's solution $(115 \mathrm{mM} \mathrm{NaCl}, 2.5 \mathrm{mM} \mathrm{KCl}$, $1.8 \mathrm{mM} \mathrm{CaCl}_{2}, 10 \mathrm{mM}$ HEPES, and $1 \mu \mathrm{M}$ atropine, $\mathrm{pH} 7.2$ ) at $2 \mathrm{ml} / \mathrm{min}$ for $\alpha 7$ and at $4 \mathrm{ml} / \mathrm{min}$ for $\alpha 4 \beta 2$. For wild-type $\alpha 7$ and $\alpha 4 \beta 2$ mutant receptors, to evaluate the effects of experimental compounds compared with ACh-evoked responses of various nAChR subtypes expressed in oocytes, control responses were defined as the average of two initial applications of ACh made before test applications. The control ACh concentrations were $60 \mu \mathrm{M}$ for the wild-type $\alpha 7$ receptor experiments and $10 \mu \mathrm{M}$ ACh for the $\alpha 4 \beta 2$ mutants. The average of independent $1 \mu \mathrm{M}$ GAT107 responses were used as the control for the $\alpha 7 \mathrm{C} 190 \mathrm{~A}$ experiments.

Solutions were applied from 96 -well plates via disposable tips. Drug applications were 12 seconds in duration followed by 181-second washout periods for $\alpha 7$ and 6 seconds in duration followed by 241second washout periods for $\alpha 4 \beta 2$. The responses were calculated as both peak current amplitudes and net charge, as previously described (Papke and Porter Papke, 2002). Data were collected at $50 \mathrm{~Hz}$, filtered at $20 \mathrm{~Hz}$, and analyzed by Clampfit 9.2 or 10.0 (Molecular Devices) and Excel (Microsoft, Redmond, WA). Data were expressed as means \pm S.E.M. from at least four oocytes for each experiment and plotted with Kaleidagraph 4.5.2 (Abelbeck Software, Reading, PA). Multicell averages were calculated for comparisons of complex responses. Averages of the normalized data were calculated for each of the 10,322 points in each of the 206.44-second traces (acquired at $50 \mathrm{~Hz}$ ) as well as the S.E.s for those averages.

Data and Statistical Analysis. The curve fits to concentrationresponse studies were generated using the Levenberg-Marquardt algorithm to obtain the best Chi-Square fit to the Hill equation using the Kalidagraph plotting program (V4.5.2). The errors reported in the Supplemental Data are the calculated S.E.s of the fit parameters based on the goodness of fit (chi square and $r$ values provided).

For comparisons of results containing three or more groups, oneway and two-way ANOVAs were used. For data for which variances were different, as measured using the Brown-Forsythe test, BrownForsythe ANOVAs were performed with Dunnett's T3 multiple comparisons test. For all other data requiring an ANOVA, ordinary one-way and two-way ANOVAs were performed with Tukey's post hoc multiple comparisons test. GraphPad Prism 8 software (San Diego, CA) was used to perform these statistical measures. GraphPad Prism 8 software was also used to generate the difference between group means or "Gardner-Altman plot" (Fig. 7B) (Ho et al., 2019). Differences of mean and confidence interval (CI) values were generated from the Tukey's post hoc multiple comparisons test.

Comparisons of all other results were made using two-tailed $t$ tests between the pairs of experimental measurements. A value of $P<0.05$ was used to constitute a minimum level of significance. These statistics were calculated using an Excel template provided in Microsoft Office.

\section{Results}

Properties of Racemic 2,3,5,6TMP-TQS. Shown in Fig. 1 are the selective effects of racemic 2,3,5,6TMP-TQS on
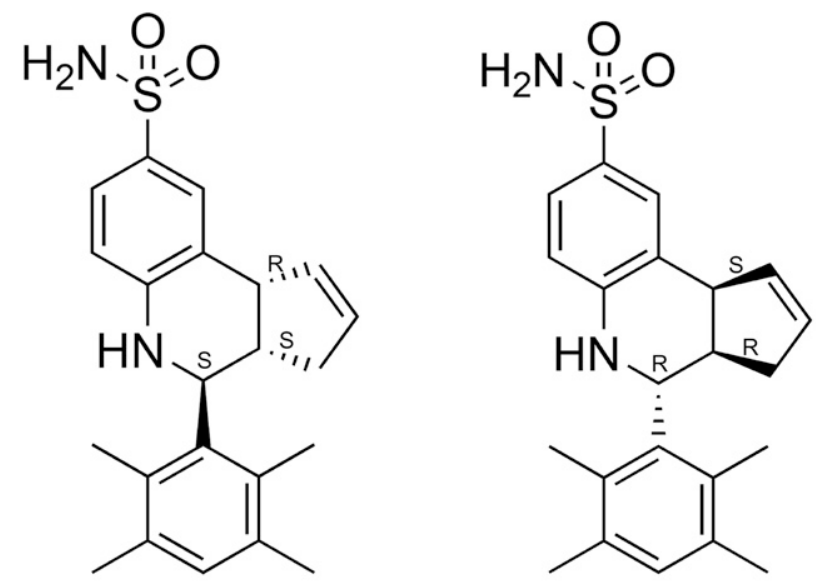

$(-) 2,3,5,6$ TMP-TQS (GAT1676)

$(+) 2,3,5,6$ TMP-TQS (GAT1677)<smiles>NS(=O)(=O)c1ccc2c(c1)[C@H]1C=CC[C@@H]1[C@H](c1cccc3ccccc13)N2</smiles><smiles>NS(=O)(=O)c1ccc2c(c1)[C@H]1C=CC[C@@H]1[C@H](c1ccc(Br)cc1)N2</smiles>

(GAT107)

$(-)$ TQS

the direct allosteric activation of $\alpha 7$ receptors by $10 \mu \mathrm{M}$ GAT107 $(P<0.001)$. With this coapplication protocol, there was no effect on the long-lived potentiation of subsequent ACh responses.

Note that the previous work (Gill-Thind et al., 2015) that reported that 2,3,5,6TMP-TQS had no effect on responses to "a submaximal concentration of ACh" relied on peak currents as measurements of $\alpha 7$ responses to $\mathrm{ACh}$ applications. However, the $\alpha 7$ peak currents responses to applications of $\mathrm{ACh}$ at concentrations $\geq 60 \mu \mathrm{M}$ occur in advance of full solution delivery (Papke and Thinschmidt, 1998), making them poor reporters of the concentration dependence of receptor activation compared with measurements of the integrated net charge of agonist-evoked responses (Papke and Porter Papke, 2002). The concentration of $100 \mu \mathrm{M}$ ACh used by Gill and coworkers is, in fact, sufficient to produce maximal net charge responses. Although 2,3,5,6TMP-TQS had no effect when applied alone to cells expressing $\alpha 7 \mathrm{nAChR}$ (Gill et al., 2012), in the course of our work with racemic 2,3,5,6TMP-TQS, we saw clear indications of 


\section{A Effects of racemic 2,3,5,6TMP-TQS and isomers on $\alpha 7$ DAA responses to GAT107}

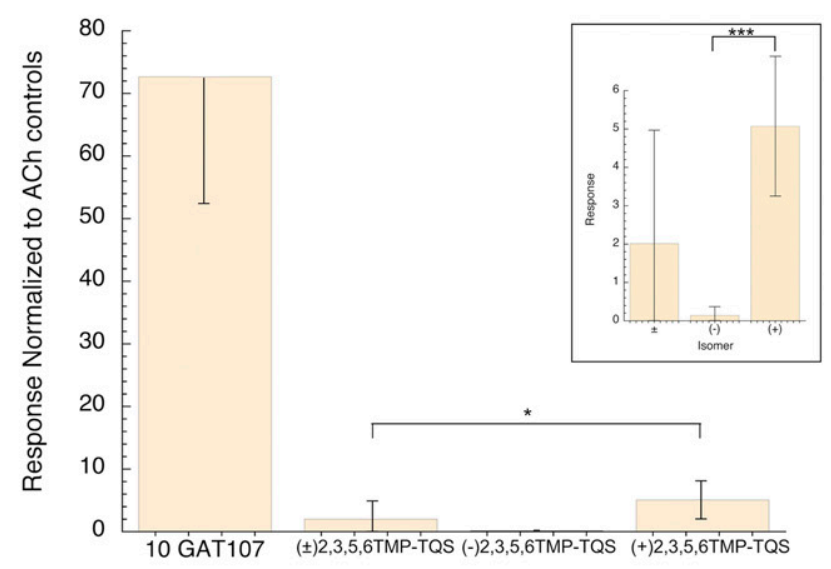

\section{B Effects of racemic 2,3,5,6TMP-TQS and isomers on} $\alpha 7$ GAT107 Primed Potentiation of ACh responses
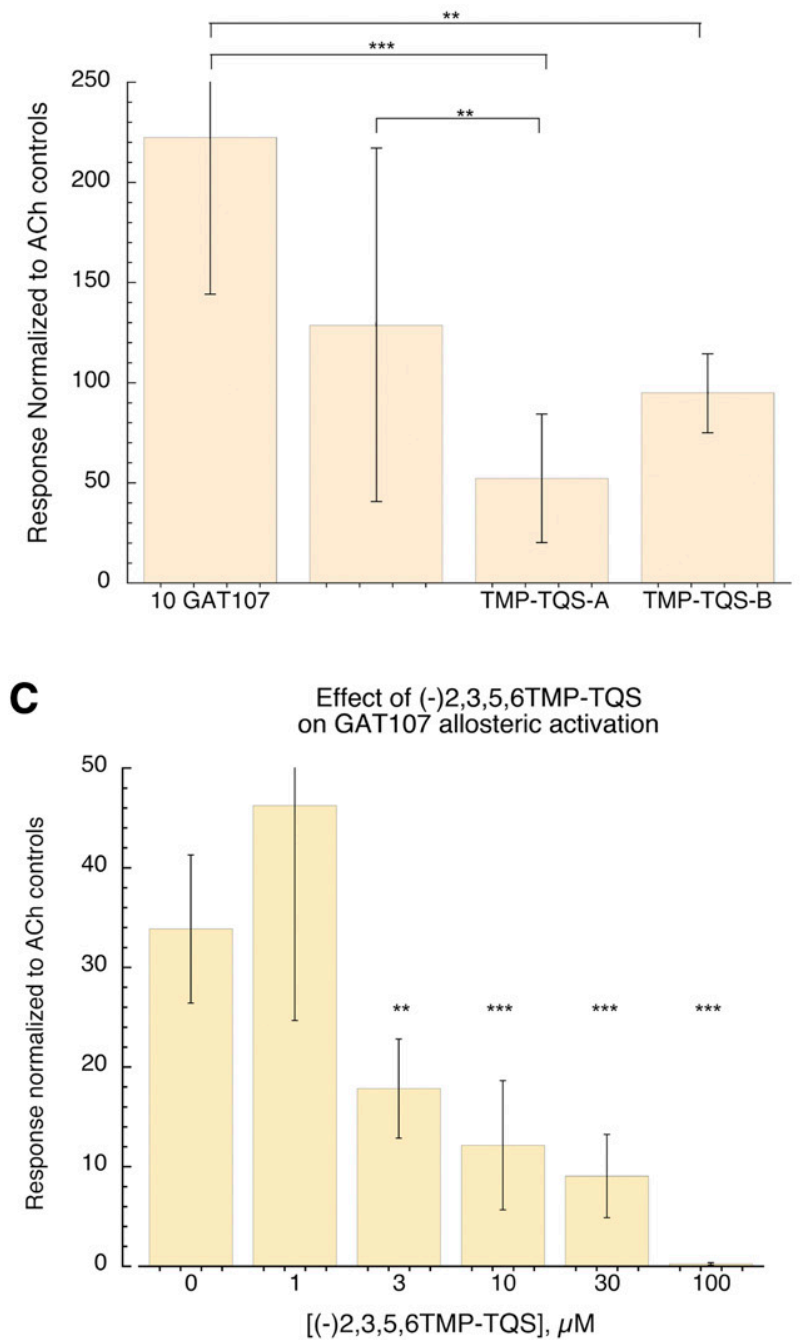

Fig. 4. 2,3,5,6TMP-TQS racemic and isomer effects on GAT107 with a preapplication/coapplication protocol. Cells were treated with Ringer's solution or $100 \mu \mathrm{M} 2,3,5,6 \mathrm{TMP}-\mathrm{TQS}$ for 30 seconds prior to application of $10 \mu \mathrm{M}$ GAT107 alone or coapplied with $100 \mu \mathrm{M}$ 2,3,5,6TMP-TQS. Data presented are averages $( \pm$ S.D.) of the responses normalized to the initial ACh controls. (A) The inhibition by (+)2,3,5,6TMP-TQS was less than by the racemic $(P=0.01)$. The $n$ values were $8,7,8$, and 8 . (B) Inhibition of

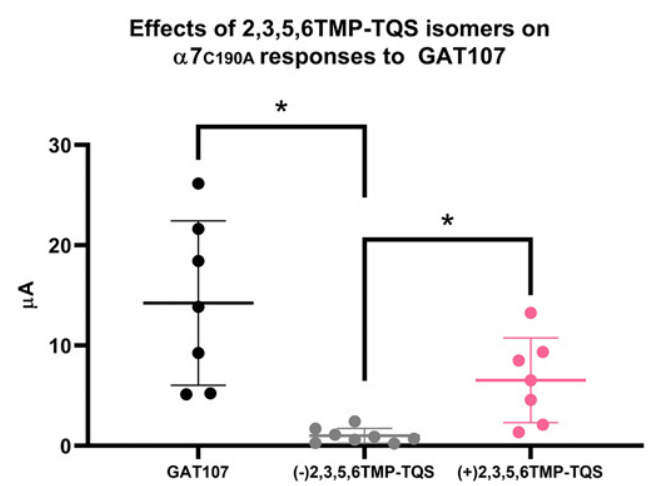

Fig. 5. 2,3,5,6TMP-TQS isomer effects on allosteric activation of the nonorthosterically activatible C190A $\alpha 7$ mutant by $10 \mu \mathrm{M}$ GAT107 (GAT107 alone, $n=7$ ). Coapplications of $10 \mu \mathrm{M}$ GAT107 with $(-)$ $2,3,5,6 \mathrm{TMP}-\mathrm{TQS}$ isomer $(n=7)$ decreased peak current responses by 93\% $(P=0.015)$, and coapplications with $(+) 2,3,5,6$ TMP-TQS $(n=8)$ decreased peak current responses by $54 \%(P=0.14)$. In addition, the inhibition by ( -$) 2,3,5,6 \mathrm{TMP}-\mathrm{TQS}$ was greater than that by $(+) 2,3,5,6 \mathrm{TMP}-$ TQS $(P=0.04)$, and $(+) 2,3,5,6 \mathrm{TMP}-\mathrm{TQS}$ did not reduce the net charge of the 10- $\mu$ M GAT107 responses. The data plotted are the individual values and the average normalized (see Materials and Methods) net charge responses \pm S.D. See Supplemental Information for detailed results of the statistical analysis. $* P<0.05$

PAM activity when the ACh concentrations were lower (Fig. 2).

Properties of 2,3,5,6TMP-TQS Isomers on GAT107 Activity with Wild-Type and Mutant $\alpha 7$. When synthesized, 2,3,5,6TMP-TQS is a racemic mixture of isomers. To test the hypothesis that PAM and allosteric antagonist activities of 2,3,5,6TMP-TQS might be associated with specific enantiomers, we separated the $(+)$ and $(-)$ enantiomers and resolved their crystal structures (Fig. 3). Also shown in Fig. 3 are the structures of the enantiomers of TQS and 4BP-TQS that we have previously shown to be the active $\alpha 7$ PAMs (Thakur et al., 2013; Stokes et al., 2019). All of these compounds have three chiral centers: two that join the cyclopentenyl ring to the quinoline and a third that connects to the aromatic rings at the base. Whereas the two that are part of the cyclopentenyl ring are constrained to orient in concert, the lower group may be either cis or trans relative to the cyclopentenyl ring of the molecule. As previously hypothesized (Gill et al., 2012), because of the steric hindrances of two ortho methyl groups, through the Povarov reaction, we only obtained trans isomers of 2,3,5,6TMP-TQS and not cis diastereomers. It was also originally hypothesized (Gill et al., 2012) that the likely transconfiguration accounted for the apparent lack of PAM activity for 2,3,5,6TMP-TQS.

We compared the effects of racemic 2,3,5,6TMP-TQS and the two isolated isomers on the two phases of GAT107 activity using a protocol with a 30-second preapplication of $100 \mu \mathrm{M}$ $2,3,5,6 \mathrm{TMP}-\mathrm{TQS}$ prior to the coapplication of $2,3,5,6 \mathrm{TMP}-$ TQS with $10 \mu \mathrm{M}$ GAT107. The racemic 2,3,5,6TMP-TQS and each isomer inhibited the direct activation by GAT107 as

primed potentiation of subsequent $\mathrm{ACh}$-evoked response with preapplication/coapplications. (C) Effect of (-)2,3,5,6TMP-TQS concentration of inhibition of the net charge of $10 \mu \mathrm{M}$ GAT107-evoked $\alpha 7$ allosteric activation with a simple coapplication protocol. The $n$ values were 7 for GAT107 alone and 8 for the coapplications. See Supplemental Information for detailed results of the statistical analysis. ${ }^{*} P<0.05, * * P<0.01, * * * P<$ 0.001 . 


\section{2,3,5,6TMP-TQS effects on B973B activity}

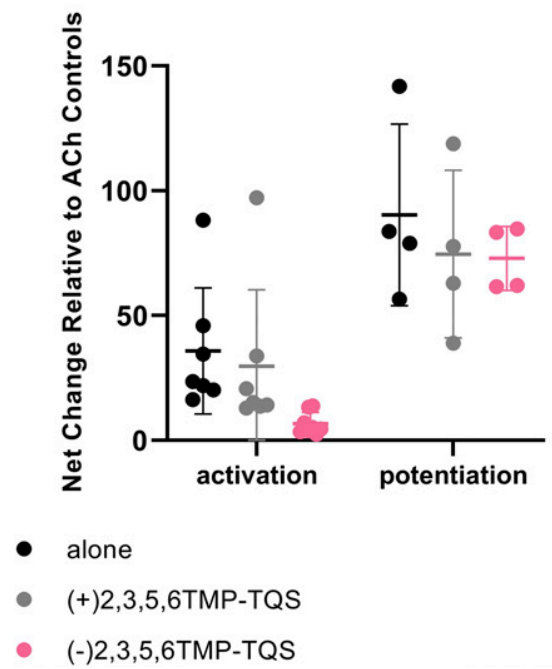

Fig. 6. Effects of 2,3,5,6TMP-TQS enantiomers on the activation and potentiation of $\alpha 7 \mathrm{nAChR}$ by B-973B. Subsequent to the acquisition of two control responses to $60 \mu \mathrm{M}$ ACh, cells expressing human $\alpha 7$ were treated with $30 \mu \mathrm{M}$ B-973B alone or coapplied with $100 \mu \mathrm{M}$ of the $2,3,5,6 \mathrm{TMP}-\mathrm{TQS}$ enantiomers. Direct allosteric activation was measured as the response to $\mathrm{B}-973 \mathrm{~B} \pm 2,3,5,6 \mathrm{TMP}-\mathrm{TQS}$. Primed potentiation was measured by comparing the response to $60 \mu \mathrm{M}$ ACh after the B-973B applications. The data shown are individual values with the average net charge responses \pm S.D. $(n=4-8)$. $(-) 2,3,5,6$ TMP-TQS reduced $(P=0.05)$ the B-973B allosteric activation. See Supplemental Information for $n$ values and detailed results of the statistical analysis.

determined by a Brown-Forsythe ANOVA $[\mathrm{F}(3,27)=15.17$, $P<0.0001$. The racemic 2,3,5,6TMP-TQS inhibited activation by GAT107 by $98 \%$, whereas (+)2,3,5,6TMP-TQS and (-) 2,3,5,6TMP-TQS are inhibited GAT107 by $93 \%$ and $99.8 \%$, respectively. Therefore, the inhibition by (+)2,3,5,6TMP-TQS was less than by the racemic ( $95 \% \mathrm{CI},-7.33$ to $-0.38, P=0.01$; Fig. 4A).

Note that with this preincubation protocol, there was also an inhibition of the potentiated ACh response after the GAT107 $[\mathrm{F}(3,27)=9.11, P=0.0002]$. Both $(+) 2,3,5,6 \mathrm{TMP}-$ TQS (95\% CI, 34.65-220.2; $P=0.004$; Fig. 4B) and (-) $2,3,5,6$ TMP-TQS (95\% CI, 77.40-262.9; $P=0.0002$; Fig. 4B) produced an inhibition of the potentiated ACh response after the GAT107. The racemic 2,3,5,6TMP-TQS also produced a small inhibition of the potentiated ACh response after the GAT107 (95\% CI, -3.13 to $188.9 ; P=0.06$; Fig. 4B), and the inhibition with (-)2,3,5,6TMP-TQS or (+)2,3,5,6TMP-TQS was equivalent to that produced by the racemic.

We tested the potency of (-)2,3,5,6TMP-TQS for inhibiting the direct activation of wild-type $\alpha 7$ produced by $10 \mu \mathrm{M}$ GAT107 with a coapplication protocol (Fig. 4C). There was inhibition at all concentrations tested $\geq 3 \mu \mathrm{M}$ using a BrownForsythe ANOVA $[\mathrm{F}(5,11.55)=22.79, P<0.0001]$ with Dunnett's T3 post hoc multiple comparisons test $(3 \mu \mathrm{M}$ : 95\% CI, 2.33-29.70; $P=0.009 ; 10 \mu \mathrm{M}$ : 95\% CI, 7.41-36.00; $P=0.0009 ; 30 \mu \mathrm{M}$ : 95\% CI, $11.27-38.31 ; P=0.0003 ; 100 \mu \mathrm{M}$ : $95 \%$ CI, 19.63-47.58; $P=0.0002$ ).

Key elements for the function of any nAChR are the disulfide-coupled vicinal cysteines (C190 and C191 in the $\alpha 7$ sequence) at the tip of the alpha subunit C-loops. Disruption of this link causes loss of function (Papke, 2014). We have previously shown that although $\alpha 7 \mathrm{C} 190 \mathrm{~A}$ mutants are
A

Isomer effects on ACh Responses

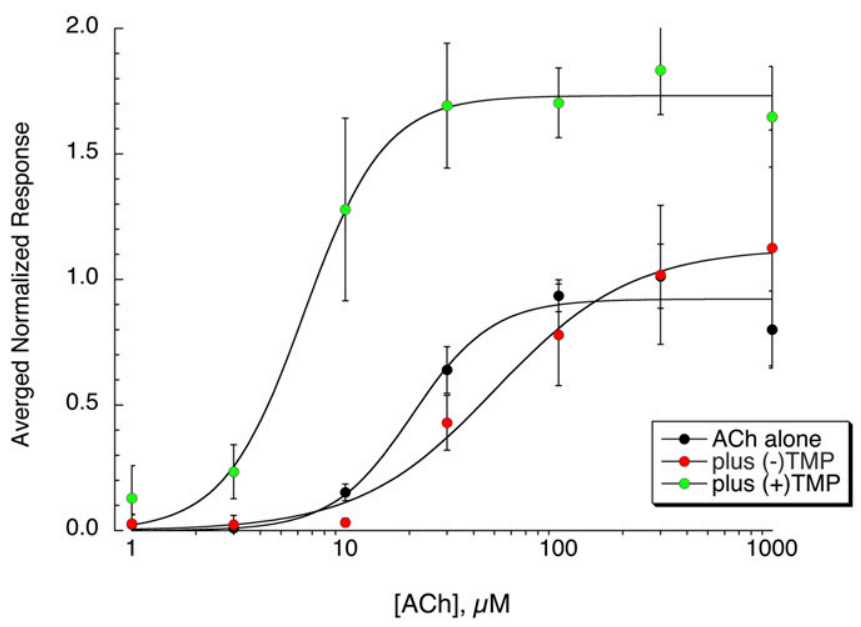

B

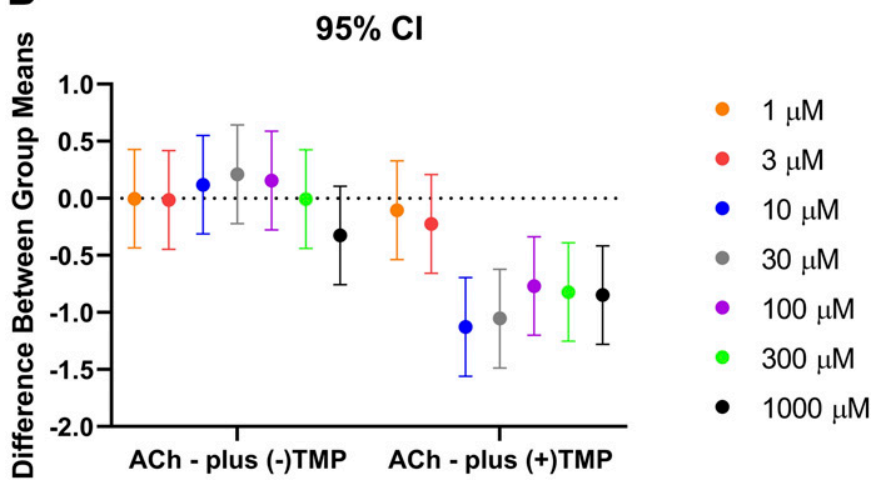

Fig. 7. Effect of 2,3,5,6TMP-TQS isomers on ACh responses of wild-type $\alpha 7$. (A) Plotted are $\alpha 7$ net charge responses across a range of ACh concentrations, with or without the coapplication of $30 \mu \mathrm{M}$ of the 2,3,5,6TMP-TQS isomers, normalized to the maximum response obtained with the application of ACh alone. Data are the averages \pm S.D. of five cells under each condition at each concentration. The curves displayed are fits to the averaged data. See Table 1 for average curve-fit values ( \pm S.D.) from the data from the individual cells and Supplemental Fig. 1 for the fit data from the single cells. ANOVA of curve fit parameters from the individual replicates are discussed in the text. Two-way ANOVAs indicate that responses to $\mathrm{ACh}$ plus (+)2,3,5,6TMP-TQS were greater than to $\mathrm{ACh}$ alone across most of the concentration range $(P>0.99,=0.91,<0.0001,<$ $0.0001,<0.0001,<0.0001$, and $<0.0001$ for $1,3,10,30,100,300$, and 1000 $\mu \mathrm{M}$ ACh, respectively). Note that the parameters of the curve fits to the averaged data shown in the figure compared with average fits of the replicates ( \pm S.D.) are given in Table 2. (B) Differences between group means are expressed as the differences between means of ACh alone and ACh plus (-)2,3,5,6TMP-TQS or ACh plus (+)2,3,5,6TMP-TQS with $95 \%$ confidence intervals at each concentration.

insensitive to ACh, even when coapplied with PNU-120596, they are effectively activated by GAT107 and that racemic 2,3,5,6TMP-TQS blocked that activation (Gulsevin et al., 2019). In basic coapplication experiments, we observed using a BrownForsythe ANOVA that both isomers reduced GAT107-evoked currents of $\alpha 7 \mathrm{C} 190 \mathrm{~A}$ [F $(2,9.09)=11.25, P=0.0035$; Fig. 5], although the inhibition by $(-) 2,3,5,6$ TMP-TQS was greater than by $(+) 2,3,5,6 \mathrm{TMP}-\mathrm{TQS}(95 \% \mathrm{CI},-0.58$ to $11.64 ; P=0.04)$.

We also tested the two 2,3,5,6TMP-TQS enantiomers for their ability to inhibit $\alpha 7$ allosteric activation by the structurally unrelated ago-PAM B-973B (Quadri et al., 2019). Like GAT107, it is able to produce allosteric activation of $\alpha 7$ receptors and potentiate the responses to $\mathrm{ACh}$. We determined 
TABLE 1

Curve fit values of the data presented in Fig. 7

These are the averages of the fits of five cells under each condition \pm S.D. See Supplemental Fig. 1 for the multiple plots and Supplemental Table 1 for individual curve fits.

\begin{tabular}{llcl}
\hline & \multicolumn{1}{c}{$\mathrm{I}_{\text {Max }}$} & $\mathrm{EC}_{50}(\mu \mathrm{M})$ & $n$ \\
\hline ACh alone & $0.92 \pm 0.10$ & $21 \pm 3.8$ & 5 \\
ACh + (-)2,3,5,6TMP-TQS & $1.16 \pm 0.47$ & $57 \pm 37$ & 5 \\
ACh + (+)2,3,5,6TMP-TQS & $1.77 \pm 0.10^{* * *}$ & $7.2 \pm 2.5^{* *}$ & 5 \\
\hline
\end{tabular}

${ }^{* * * *} P<0.0001$ compared with ACh alone; **P<0.001 compared with ACh alone.

that ( - ) 2,3,5,6TMP-TQS (95\% CI, -0.45 to $58.67 ; P=0.05$ ), but not (+)2,3,5,6TMP-TQS (95\% CI, -24.38 to $36.68 ; P=0.87$ ), was also an effective antagonist of allosteric activation by B-973B $[F(2,19)=3.55, P=0.049 ;$ Fig. 6$]$. Neither enantiomer had any effect on the residual potentiation produced by this agent $[\mathrm{F}(2$, 9) $=0.42, P=0.67]$.

PAM Activity of 2,3,5,6TMP-TQS Isomers. We conducted ACh concentration-response studies with or without coapplication of the 2,3,5,6TMP-TQS isomers at $30 \mu \mathrm{M}$ (Fig. 7). Visual inspection of the curves suggests that (+) $2,3,5,6 \mathrm{TMP}-\mathrm{TQS}$ functions as a PAM and (-)2,3,5,6TMP-TQS does not. We use several statistical approaches to confirm this using both the averaged data (Fig. 7) and an analysis of the concentration-response data of individual cells $(n=5$ under each condition, see Supplemental Data). Specifically, using two-way ANOVA, we found an interaction effect between ACh concentration and coapplication $[\mathrm{F}(12,91)=10.21, P<0.0001$; Fig. 7A]. Effects of (+)2,3,5,6TMP-TQS were seen across almost the entire concentration range $(10-1000 \mu \mathrm{M}$; Fig. 7B), including maximally effective concentrations $\geq 100 \mu \mathrm{M}$. When analyzing curve fit parameters by Brown-Forsythe ANOVA $\left[\mathrm{EC}_{50}: \mathrm{F}(2,12)=6.97, P=0.05\right) ; \mathrm{I}_{\max }: \mathrm{F}(2,12)=11.69$, $P=0.01]$, the concentration-response function for net charge responses (Papke and Porter Papke, 2002) was relatively unaffected by addition of $(-) 2,3,5,6 \mathrm{TMP}-\mathrm{TQS}$ $\left(\mathrm{EC}_{50}: P=0.17\right.$; $\left.\mathrm{I}_{\max }: P=0.53\right)$; however, $(+) 2,3,5,6 \mathrm{TMP}-$ TQS increased ACh potency by $65 \%(P=0.0006)$ and efficacy by $91 \%(P<0.0001)$ (Table 1$)$. We then ran an ANOVA for the $\operatorname{logEC} \mathrm{E}_{50}$ values with responses normalized as a percentage of the average responses across five replicates $[\mathrm{F}(2,12)=26.10, P<0.0001]$. We saw that addition of $(-)$ $2,3,5,6 \mathrm{TMP}-\mathrm{TQS}$ caused a similar decrease in potency (95\% CI, -0.67 to $-0.08 ; P=0.015)$ and an increase in potency with addition of (+)2,3,5,6TMP-TQS (95\% CI, 0.18-0.77; $P=0.003$ ). When calculating the inverse $\log$ from $\log \mathrm{EC}_{50}$, values for $\mathrm{EC}_{50}$ using this method were consistent, as ACh alone was $20.61 \mu \mathrm{M}$ with the addition of (-)2,3,5,6TMP-TQS at $48.52 \mu \mathrm{M}$ and (+) $2,3,5,6 \mathrm{TMP}-\mathrm{TQS}$ at $6.87 \mu \mathrm{M}$.
Although all of these analyses confirm the PAM activity of (+)2,3,5,6TMP-TQS, it should be noted that the magnitude of the (+)2,3,5,6TMP-TQS potentiation was at least an order of magnitude less than previously reported for (-)TQS (Stokes et al., 2019) or GAT107 [(+)4BP-TQS] (Papke et al., 2014).

2,3,5,6TMP-TQS Isomer Effects on Mutant a4ß2 Receptors Sensitive to $\alpha 7$ PAMs. We have recently described a point mutation $\left(\mathrm{L}^{\prime} 5^{\prime} \mathrm{M}\right)$ in the second transmembrane domain of neuronal $\beta$ subunits that results in heteromeric neuronal nAChR that are sensitive to select $\alpha 7$ PAMs in the TQS family (Stokes et al., 2019). In $\alpha 7$, this residue is a methionine, and the opposite mutation results in a loss of PAM sensitivity.

We have previously shown that the inclusion of a single mutant subunit is sufficient to produce sensitivity to $\alpha 7$ PAMs and that the presence of additional mutant subunits reduces receptor function (Stokes et al., 2019). To obtain $\alpha 4 \beta 2$ receptors with a single $\beta 2 \mathrm{~L} 15^{\prime} \mathrm{M}$ mutant subunit, we coexpressed a $\beta 2-\alpha 4$ concatamer (Zhou et al., 2003) with monomeric $\beta 2 \mathrm{~L} 15^{\prime} \mathrm{M}$. The coapplication of $(-) 2,3,5,6 \mathrm{TMP}-\mathrm{TQS}$ with ACh gave a small increase in peak current $(P<0.01)$ but had no effect on net charge (Fig. 8). In contrast, coapplication of (+)2,3,5,6TMP-TQS with ACh produced large increases in both peak current and net charge responses $(P<0.001)$, as would be expected for a Type II PAM (Gronlien et al., 2007). The coapplication of (+)2,3,5,6TMP-TQS increased peak current and net charge by an average $5.7 \pm$ 0.3 - and $4.6 \pm 0.6$-fold, respectively $(n=8, P<0.001)$.

2,3,5,6TMP-TQS Isomer Effects on the Allosteric Activation of Mutant $\alpha 4 \beta 2$ Receptors. In our initial characterization of heteromeric neuronal $\mathrm{nAChR}$ sensitive to $\alpha 7$ PAMs (Stokes et al., 2019), we identified GAT927 as an extremely potent and efficacious PAM for these mutant heteromeric receptors. In addition to strongly potentiating ACh-evoked responses, we noted that, when applied alone, high concentrations of GAT927 produced direct allosteric activation, analogous to GAT107's effects on $\alpha 7$ (Fig. 9A). We tested the hypothesis that (-)2,3,5,6TMP-TQS, the isomer

TABLE 2

Parameters of the fit shown in Fig. 7 to the averaged data at each concentration compared with average values $( \pm$ S.D.) of the fits of the replicates shown in Table 1 (see Supplemental Data)

The errors reported for the fit parameters to the averaged data are the calculated S.E.s of the fit parameters based on the goodness of fit (chi square and $r$ values, see Materials and Methods).

\begin{tabular}{|c|c|c|c|c|c|}
\hline & \multicolumn{2}{|c|}{ Fits of Averaged Data } & \multicolumn{2}{|c|}{ Fits of Separate Replicates } & \multirow[b]{2}{*}{$n$} \\
\hline & $\mathrm{I}_{\mathrm{Max}}$ & $\mathrm{EC}_{50}(\mu \mathrm{M})$ & $\mathrm{I}_{\mathrm{Max}}$ & $\mathrm{EC}_{50}(\mu \mathrm{M})$ & \\
\hline ACh alone & $0.92 \pm 0.005$ & $20.65 \pm 3.4$ & $0.92 \pm 0.10$ & $21 \pm 3.8$ & 5 \\
\hline $\mathrm{ACh}+(-) 2,3,5,6 \mathrm{TMP}-\mathrm{TQS}$ & $1.13 \pm 0.06$ & $50.6 \pm 7.9$ & $1.16 \pm 0.47$ & $57 \pm 37$ & 5 \\
\hline $\mathrm{ACh}+(+) 2,3,5,6 \mathrm{TMP}-\mathrm{TQS}$ & $1.73 \pm 0.05$ & $6.4 \pm 0.64$ & $1.77 \pm 0.10^{* * *}$ & $7.2 \pm 2.5^{* *}$ & 5 \\
\hline
\end{tabular}

${ }^{* * *} P<0.01 ; * * * P<0.001$. 
A
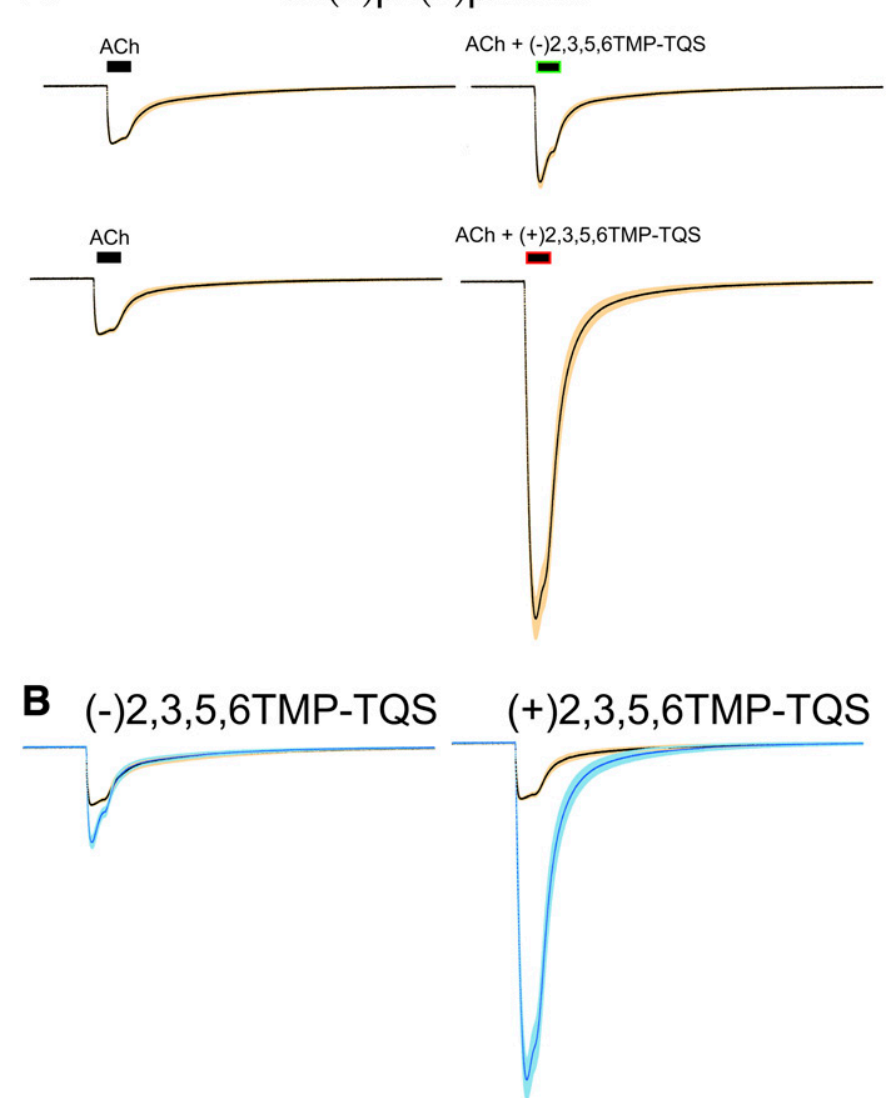

Fig. 8. The sensitivity of $\alpha 4 \beta 2$ receptors containing a single $\beta 2 \mathrm{~L} 15^{\prime} \mathrm{M}$ subunit to coapplications of $2,3,5,6 \mathrm{TMP}-\mathrm{TQS}$ isomers. (A) Averaged raw data traces normalized to $10 \mu \mathrm{M}$ control ACh responses from the same cells $(n=8)$ to ACh alone or ACh coapplied with $30 \mu \mathrm{M}$ of the 2,3,5,6TMP-TQS isomers. (B) Superimposed traces from (A). The data in blue are those obtained with coapplication of $30 \mu \mathrm{M} 2,3,5,6 \mathrm{TMP}-\mathrm{TQS}$ isomers.

better for antagonizing $\alpha 7$ allosteric activation, would also more effectively antagonize the allosteric activation of the $\alpha 4 \beta 2$ mutant receptor by GAT927. Whereas (-)2,3,5,6TMPTQS did decrease GAT927 allosteric activation $(P<0.05$, Fig. 9B), activation by GAT927 was totally eliminated by (+) $2,3,5,6 \mathrm{TMP}-\mathrm{TQS}$ (Fig. 9C). Interestingly, the effects of the $2,3,5,6 \mathrm{TMP}-\mathrm{TQS}$ isomers were restricted to the period of direct allosteric activation by GAT927, and the primed potentiation for a subsequent ACh-evoked response was unaffected (Fig. 9D). As noted above, neither of the isomers had an effect on the net charge or peak current amplitude of these responses. However, although the responses shown in Fig. 9, A and B had not decayed fully to baseline after the GAT927 applications (baselines were $82 \% \pm 27 \%$ and $107 \% \pm 22 \%$ the amplitude of the ACh controls, respectively), the trace in Fig. 9C (magenta in Fig. 9D) actually began with a lower baseline current than the initial control $(P<0.001)$.

In Silico Model of (-)2,3,5,6TMP-TQS in the Putative Allosteric Activation Site of $\boldsymbol{\alpha} 7$. We (Horenstein et al., 2016; Gulsevin et al., 2019) and others (Spurny et al., 2015) have proposed models for an allosteric ligand binding site in the extracellular vestibule of $\alpha 7$ receptors. We compared the docking of GAT107 and the most active antagonist (-) 2,3,5,6TMP-TQS into that site (Fig. 10) and found that (-) 2,3,5,6TMP-TQS was notably different from GAT107 in that, despite an overall similar binding mode, it presented its fused cyclopentenyl ring to T106, whereas the other compound did not.

We hypothesized that this interaction would be lost with a T106A mutation (Fig. 9D). Using a coapplication protocol, we confirmed that $30 \mu \mathrm{M}(-) 2,3,5,6 \mathrm{TMP}-\mathrm{TQS}$ produced good inhibition of GAT107 allosteric activation of wild-type $\alpha 7$ $(P<0.001)$ with no effect on the potentiation of subsequent ACh responses (Fig. 11A). Using the same protocol with $\alpha 7 \mathrm{~T} 106 \mathrm{~A}$, we saw no changes with $30 \mu \mathrm{M}(-) 2,3,5,6 \mathrm{TMP}-$ TQS on either GAT107 allosteric activation or subsequent potentiation (Fig. 11B).

\section{Discussion}

Stereoisomerism is a critical concern when designing drugs for enzymes and receptors because stereoisomers can and often do display different pharmacology. Whereas molecules with a single chiral center will be capable of existing as a pair of enantiomers, molecules with multiple chiral centers $N$ will have $2^{N}$ maximum possible stereoisomers, as exemplified by the ring system of 2,3,5,6TMP-TQS, which has three chiral centers and eight theoretically possible stereoisomers, including enantiomers and diastereomers. However, as noted previously, constraints on the cyclopentenyl ring and steric hindrances associated with two ortho methyl groups resulted in exclusive formation and isolation of the trans diastereomer. Although most biologic processes that form organic molecules with chiral centers tend to produce single stereoisomers, such as D-sugars and L-amino acids, test tube reactions commonly produce racemic mixtures of isomers. When these reaction products are then used experimentally, the biologic response may or may not be deferentially sensitive to the component isomers.

In biologic systems, the requirement for isomer specificity is a function of the receptor and the flexibility of the ligand. Our right foot will readily accept either of a pair of socks but shows a strong preference for only one of a pair of shoes. In the case of $\mathrm{nAChR}$, although the ACh binding site of muscle-type receptors shows a preference for the naturally occurring $(-)$ isomer of nicotine, both isomers are equally effective as low potency blockers of the ion channel (Rozental et al., 1989). Likewise, both isomers of the neuronal nAChR noncompetitive antagonist mecamylamine have similar efficacy for blocking channel activity of a wide variety of heteromeric neuronal nAChR (Papke et al., 2001, 2013).

The amino acid residues in neuronal $\beta$ subunits that determine sensitivity to mecamylamine face into the ion permeation pathway and are present in at least two subunits per heteromeric pentamer (Webster et al., 1999). The dimensions of the open pore and the presence of multiple binding sites may both be permissive factors for the lack of mecamylamine's stereoselectivity. In contrast, although the $\alpha 7$ PAM binding site is likely present in all subunits and requires a specific residue in the pore-forming second transmembrane domain, the actual binding orientation of the modulator is likely to be within a hydrophobic cavity within the transmembrane helices (Young et al., 2008; Collins and Millar, 2010; Newcombe et al., 2018). In this tight pocket, stereochemical constraints appear to be very important. This was shown to be the case for three functionally diverse analogs in the TQS family, TQS itself (Stokes et al., 2019), the ago-PAM 
$\alpha 4(2) \beta 2(2) \beta 2 \mathrm{~L} 155^{\prime} \mathrm{M}$
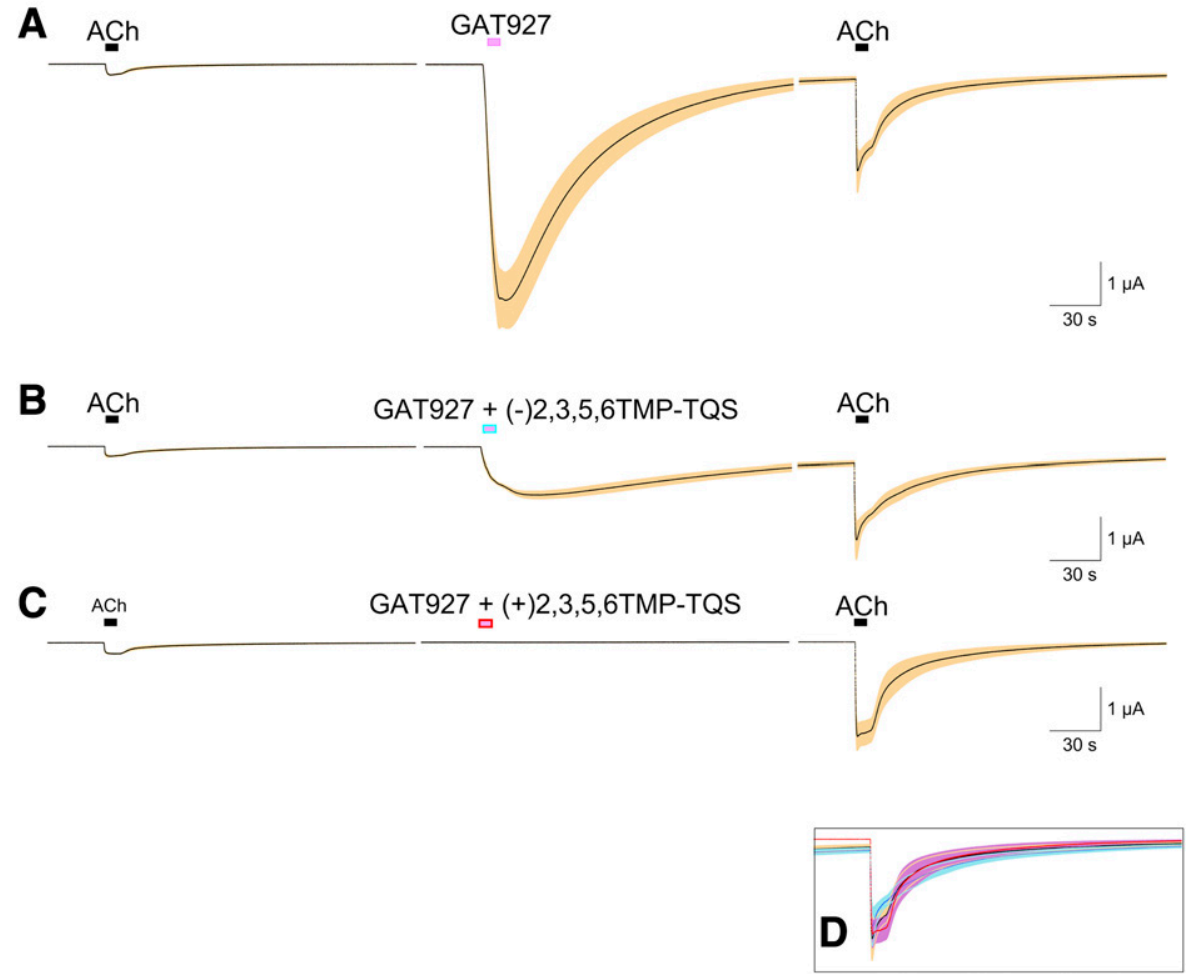

Fig. 9. The allosteric activation of $\alpha 4(2) \beta 2(2) \beta$ $2 \mathrm{~L} 15^{\prime} \mathrm{M}$ receptors by GAT927 and sensitivity of GAT927 responses to coapplications of 2,3,5,6TMPTQS isomers. (A) Application of the TQS analog GAT927 at $30 \mu \mathrm{M}$ to cells expressing $\alpha 4 \beta 2$ receptors with a mutant $\beta 2$ subunit production of allosteric activation and primed potentiation of subsequent ACh responses $(n=6)$. (B) The coapplication of $100 \mu \mathrm{M}(-) 2,3,5,6 \mathrm{TMP}-\mathrm{TQS}$ with $30 \mu \mathrm{M}$ GAT927 $(n=7)$ reduced the allosteric activation net charge $(P<0.005)$, with no effect on the primed potentiation of subsequent $\mathrm{ACh}$ responses. (C) The coapplication of $100 \mu \mathrm{M}(+) 2,3,5,6 \mathrm{TMP}-\mathrm{TQS}$ with $30 \mu \mathrm{M}$ GAT927 $(n=7)$ eliminated the allosteric activation net charge $(P<0.0001)$, also with no effect on the primed potentiation of subsequent ACh responses. (D) An overlay of the three postGAT927 application ACh responses.
4BP-TQS (Thakur et al., 2013; Papke et al., 2014), and the allosteric antagonist presented in this work, 2,3,5,6TMP-TQS, as well as for the structurally unrelated ago-PAM B-973B (Garai et al., 2018; Quadri et al., 2019). Additionally, a recently published study of a family of sulfonamide-containing PAMs showed that the stereochemical orientation of side groups around a critical central cyclopropyl ring determine whether enantiomers function as Type I or Type II $\alpha 7$ PAMs (Harvey et al., 2019; Wang et al., 2020).

To better understand the important structural elements of TQS-related PAMs, we made a structural comparison of $(-)$ TQS and (+)2,3,5,6TMP-TQS (Fig. 12). The comparison reveals considerable similarity in the overall three-dimensional shape of the fused ring system, consisting of the arylsulfonamide, piperidine, and cyclopentenyl rings. It is notable that, although TQS is cis with regard to the cyclopentenyl and napthyl rings, (+)2,3,5,6TMP-TQS has a trans relationship between the cyclopentenyl and tetramethylbenzene rings. Despite this, the superposition revealed that the bulky napthyl and tetramethylphenyl rings occupied the region in space in the overlay. This comparative analysis suggests that the basis for the PAM activity of (+)2,3,5,6TMP-TQS arises from its overall similarity to the shape of TQS despite the difference in stereochemistry of the ring fusions. Further comparison with (+)4BP-TQS (GAT107) (Fig. 3) suggests that possibly the most crucial feature for PAM activity is the orientation of cyclopentenyl ring away from the plane of napthyl ring.
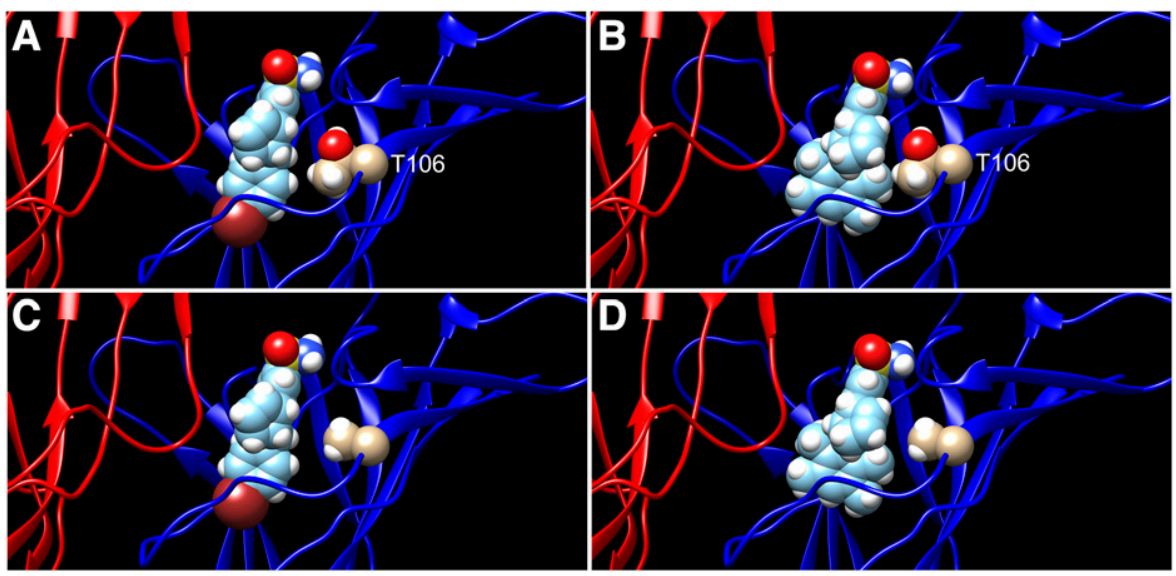

Fig. 10. Using methods previously described (Gulsevin et al., 2019), GAT107 (A) and (-) 2,3,5,6TMP-TQS (B) were docked into a homology model of the $\alpha 7$ extracellular domain. The orientation of $(-) 2,3,5,6 \mathrm{TMP}-\mathrm{TQS}$ in the putative allosteric activation site suggested a close association with the T106 residue (shown) that was not present with GAT107. (C and D) The same models with the threonine residue converted to alanine. 
A

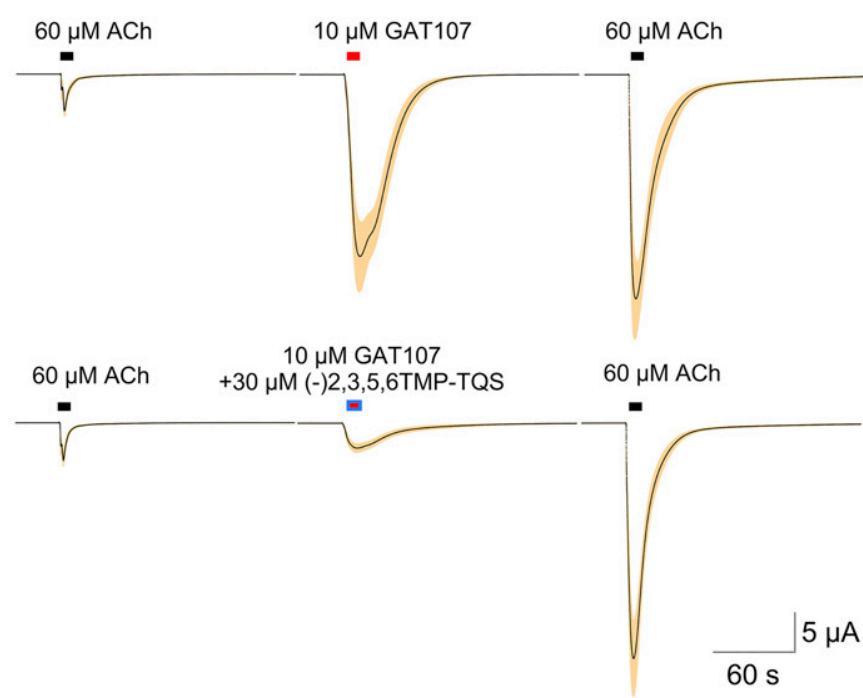

B
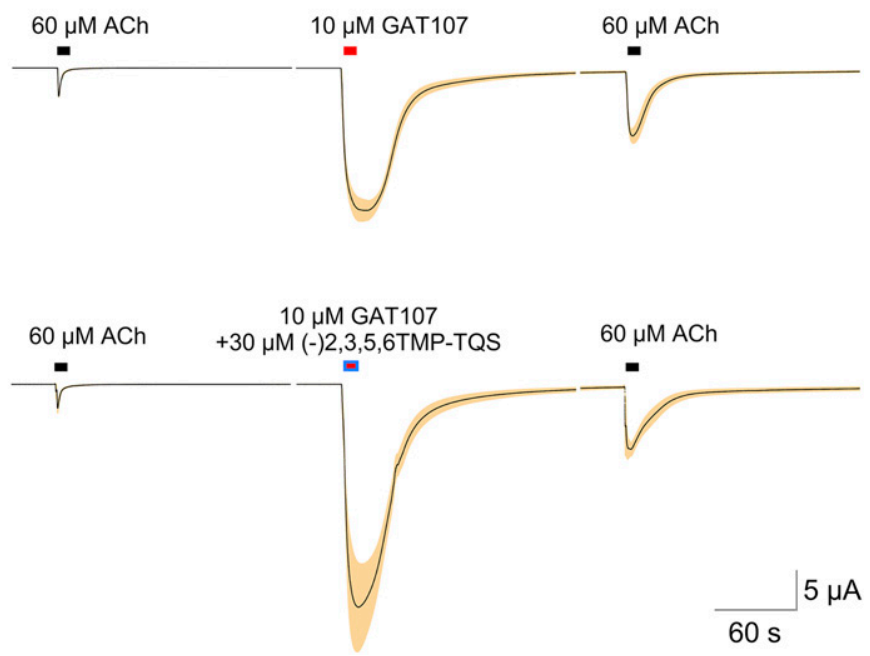

Fig. 11. The effects of (-)2,3,5,6TMP-TQS on GAT107 responses of wildtype and T106A mutant $\alpha 7$ receptors. (A) Wild-type receptors $(n=6)$ show a selective inhibition $(P \leq 0.001)$ of allosteric activation by $30 \mu \mathrm{M}(-)$ 2,3,5,6TMP-TQS. (B) GAT107 responses of cells expressing $\alpha 7 \mathrm{~T} 106 \mathrm{~A}$ were unaffected by coapplication of $30 \mu \mathrm{M}(-) 2,3,5,6 \mathrm{TMP}-\mathrm{TQS}$. Averaged raw data traces for cells ( $n=4$, see Materials and Methods) were normalized to the control responses to $60 \mu \mathrm{M}$ ACh shown. The S.E.M. of the averaged normalized responses are represented by the tan colored areas.

Structural models for the transmembrane domains of $\alpha 7$ have been proposed based on the relatively low-resolution images of the muscle-type Torpedo receptor and suggestions made for how PAMs may bind in these domains (Gill et al., 2011; Newcombe et al., 2018). However, not only are muscletype receptors insensitive to $\alpha 7 \mathrm{PAMs}$, but also the key L15' $\mathrm{M}$ mutation that permits heteromeric neuronal $\mathrm{nAChR}$ to respond to TQS-type PAMs are ineffective in muscle $\mathrm{nAChR}$, so the predictive values of these models may be extremely limited. We are optimistic that in the future, structures of PAM-sensitive mutant heteromeric receptors will become available, which will allow further insights into the critical differences between the binding of active and inactive isomers

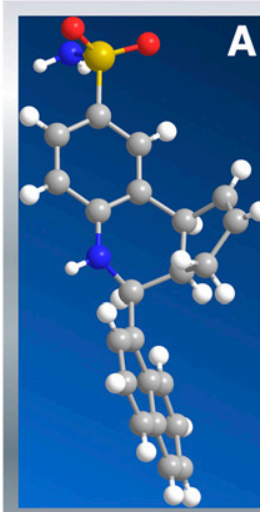

$(-) T Q S$

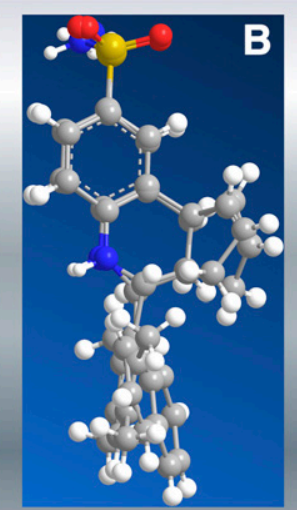

Overlay

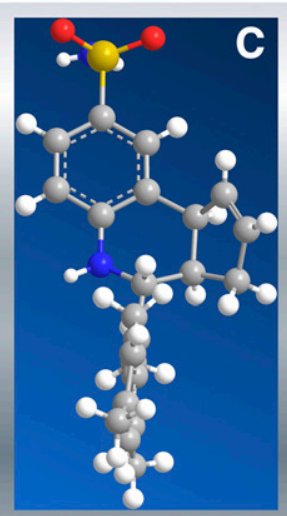

$(+) 2,3,5,6$ TMP-TQS
Fig. 12. Ball and stick figures and molecular superposition of the PAMs (-)TQS and (+)2,3,5,6TMP-TQS. (A) (-)TQS, (B) superposition, and (C) (+) $2,3,5,6$ TMP-TQS.

(Stokes et al., 2019), as both $\alpha 7$ and $\alpha 4 \beta 2$ L15'M receptors discriminate the same way between the isomers of both TQS and 2,3,5,6TMP-TQS.

Although the PAM binding sites of both $\alpha 7$ and $\alpha 4 \beta 2$ L15'M receptors may be similar, the mechanism of allosteric activation of these receptors by GAT107 and GAT927, respectively, seems to be different (Stokes et al., 2019). Although we can suggest a specific allosteric agonist site on $\alpha 7$ (Gulsevin et al., 2019), there is limited evidence for a similar site on $\alpha 4 \beta 2$ L15'M receptors. However, whereas GAT107 does not produce allosteric activation of these receptors (Stokes et al., 2019), both isomers of 2,3,5,6TMP-TQS do antagonize allosteric activation by GAT927, albeit with reverse stereoselectivity than for allosteric antagonism of $\alpha 7$. The observation that neither 2,3,5,6TMP-TQS isomer reduced the potentiation of subsequent $\mathrm{ACh}$ response would suggest that the antagonism of GAT927 allosteric activation is not due to binding at the transmembrane PAM site.

An important consideration is that previous work that relied on the use of racemic mixtures of compounds from the TQS family (Gill et al., 2012; Gill-Thind et al., 2015; Horenstein et al., 2016; Newcombe et al., 2018) should be viewed with circumspection. Whereas racemic 4BP-TQS is a mixture of active and inactive compounds that merely has the impact of lowering the effective concentration, racemic TQS is, in fact, a mixture of a PAM and a molecule that antagonizes that activity (Stokes et al., 2019). As we show in this study, racemic $2,3,5,6 \mathrm{TMP}-\mathrm{TQS}$ carries a mixture of two different activities. 2,3,5,6TMP-TQS was 1 of a total of 17 TQS analogs with varying activity that were reported in a single study (Gill et al., 2012), and all were characterized as racemic mixtures, where one isomer may have obscured the properties of another. We have also evaluated many additional TQS analogs as racemic mixtures, including GAT154, GAT155, GAT904, and GAT193 (Horenstein et al., 2016). Likewise, the ago-PAM of mutant heteromeric receptors, GAT927, was used as a racemic mixture in these and previous experiments (Stokes et al., 2019). It seems likely that the efforts required to isolate the isomers of various compounds would be rewarded by the revelation of pharmacological diversity richer than we might imagine, with the identification of relatively 
selective compounds that would not only inform further structural studies but also have improved therapeutic potential.

The results of docking (Fig. 10) suggested that the antagonist activity of (-)2,3,5,6TMP-TQS at the allosteric activation site would, at least in part, arise from a unique interaction with T106. The electrophysiological evaluation of mutation T106A provided support for this hypothesis via the observation that, relative to wild-type, (-)2,3,5,6TMP-TQS lost the ability to antagonize the allosteric activation by GAT107. The mechanism by which T106 is required for (-)2,3,5,6TMP-TQS antagonism remains unclear. It is possible that the interaction with T106 is required for (-)2,3,5,6TMP-TQS to bind with high affinity as an antagonist. Alternatively, T106 may cause $(-) 2,3,5,6 \mathrm{TMP}-\mathrm{TQS}$ to adopt a conformation that is intrinsically inactive. Possibly both of these things are factors. We have confirmed that (-)2,3,5,6TMP-TQS does not become an allosteric agonist for $\alpha 7 \mathrm{~T} 106 \mathrm{~A}$, as coapplication with PNU120596 does not evoke a response (data not shown).

An important conclusion that emerges from the combination of docking and mutagenesis studies is that they provide strong support for the location of the AA binding site. It is instructive to learn that subtle changes in the interactions of a bound ligand can have such a divergent impact on receptor function, confirming that the AA site should be a continued target of interest for development of new modulators of $\alpha 7$ function.

\section{Acknowledgments}

We thank Lu Wenchi Corrie for conducting oocyte recordings.

\section{Authorship Contributions}

Participated in research design: Papke, Stokes.

Conducted experiments: Garai, Stokes, Abboud.

Contributed new reagents or analytic tools: Garai, Thakur.

Performed data analysis: Papke, Horenstein, Zimmerman.

Wrote or contributed to the writing of the manuscript: Papke, Stokes, Horenstein, Zimmerman, Abboud, Thakur.

\section{References}

Bertrand D and Gopalakrishnan M (2007) Allosteric modulation of nicotinic acetylcholine receptors. Biochem Pharmacol 74:1155-1163.

Changeux J-P (1981) The Acetylcholine Receptor: An "Allosteric" Membrane Protein, Academic Press Inc., New York.

Collins T and Millar NS (2010) Nicotinic acetylcholine receptor transmembrane mutations convert ivermectin from a positive to a negative allosteric modulator. Mol Pharmacol 78:198-204.

Garai S, Raja KS, Papke RL, Deschamps JR, Damaj MI, and Thakur GA (2018) B-973, a novel $\alpha 7 \mathrm{nAChR}$ ago-PAM: racemic and asymmetric synthesis, electrophysiological studies, and in vivo evaluation. ACS Med Chem Lett 9:1144-1148.

Gill JK, Dhankher P, Sheppard TD, Sher E, and Millar NS (2012) A series of $\alpha 7$ nicotinic acetylcholine receptor allosteric modulators with close chemical similarity but diverse pharmacological properties. Mol Pharmacol 81:710-718.

Gill JK, Savolainen M, Young GT, Zwart R, Sher E, and Millar NS (2011) Agonist activation of alpha7 nicotinic acetylcholine receptors via an allosteric transmembrane site. Proc Natl Acad Sci USA 108:5867-5872.

Gill-Thind JK, Dhankher P, D'Oyley JM, Sheppard TD, and Millar NS (2015) Structurally similar allosteric modulators of $\alpha 7$ nicotinic acetylcholine receptors exhibit five distinct pharmacological effects. J Biol Chem 290:3552-3562.

Gulsevin A, Papke RL, Stokes C, Garai S, Thakur GA, Quadri M, and Horenstein NA (2019) Allosteric Agonism of $\alpha 7$ Nicotinic Acetylcholine Receptors: Receptor Modulation Outside the Orthosteric Site. Mol Pharmacol 95:606-614.

Halevi S, Yassin L, Eshel M, Sala F, Sala S, Criado M, and Treinin M (2003) Conservation within the RIC-3 gene family. Effectors of mammalian nicotinic acetylcholine receptor expression. J Biol Chem 278:34411-34417.

Harvey AJ, Avery TD, Schaeffer L, Joseph C, Huff BC, Singh R, Morice C, Giethlen B, Grishin AA, Coles CJ, et al. (2019) Discovery of BNC375, a potent, selective, and orally available type I positive allosteric modulator of $\alpha 7 \mathrm{nAChRs}$. ACS Med Chem Lett 10:754-760.

Ho J, Tumkaya T, Aryal S, Choi H, and Claridge-Chang A (2019) Moving beyond P values: data analysis with estimation graphics. Nat Methods 16:565-566.

Horenstein NA, Papke RL, Kulkarni AR, Chaturbhuj GU, Stokes C, Manther K, and Thakur GA (2016) Critical molecular determinants of $\alpha 7$ nicotinic acetylcholine receptor allosteric activation: separation of direct allosteric activation and positive allosteric modulation. $J$ Biol Chem 291:5049-5067.

Hurst RS, Hajós M, Raggenbass M, Wall TM, Higdon NR, Lawson JA, RutherfordRoot KL, Berkenpas MB, Hoffmann WE, Piotrowski DW, et al. (2005) A novel positive allosteric modulator of the alpha7 neuronal nicotinic acetylcholine receptor: in vitro and in vivo characterization. $J$ Neurosci 25:4396-4405.

Kulkarni AR and Thakur GA (2013) Microwave-assisted expeditious and efficient synthesis of cyclopentene ring-fused tetrahydroquinoline derivatives using threecomponent Povarov reaction. Tetrahedron Lett 54:6592-6595.

Newcombe J, Chatzidaki A, Sheppard TD, Topf M, and Millar NS (2018) Diversity of nicotinic acetylcholine receptor positive allosteric modulators revealed by mutagenesis and a revised structural model. Mol Pharmacol 93:128-140.

Papke RL (2014) Merging old and new perspectives on nicotinic acetylcholine receptors. Biochem Pharmacol 89:1-11.

Papke RL, Horenstein NA, Kulkarni AR, Stokes C, Corrie LW, Maeng CY, and Thakur GA (2014) The activity of GAT107, an allosteric activator and positive modulator of $\alpha 7$ nicotinic acetylcholine receptors (nAChR), is regulated by aromatic amino acids that span the subunit interface. J Biol Chem 289:4515-4531.

Papke RL and Porter Papke JK (2002) Comparative pharmacology of rat and human alpha7 nAChR conducted with net charge analysis. Br J Pharmacol 137:49-61.

Papke RL, Sanberg PR, and Shytle RD (2001) Analysis of mecamylamine stereoisomers on human nicotinic receptor subtypes. J Pharmacol Exp Ther 297: 646-656.

Papke RL and Stokes C (2010) Working with OpusXpress: methods for high volume oocyte experiments. Methods 51:121-133.

Papke RL, Stokes C, Damaj MI, Thakur GA, Manther K, Treinin M, Bagdas D, Kulkarni AR, and Horenstein NA (2018) Persistent activation of $\alpha 7$ nicotinic ACh receptors associated with stable induction of different desensitized states. $\mathrm{Br}$ $J$ Pharmacol 175:1838-1854.

Papke RL, Stokes C, Muldoon P, and Imad Damaj M (2013) Similar activity of mecamylamine stereoisomers in vitro and in vivo. Eur J Pharmacol 720:264-275.

Papke RL, Stokes C, Williams DK, Wang J, and Horenstein NA (2011) Cysteine accessibility analysis of the human alpha7 nicotinic acetylcholine receptor ligandbinding domain identifies L119 as a gatekeeper. Neuropharmacology 60:159-171.

Papke RL and Thinschmidt JS (1998) The correction of alpha7 nicotinic acetylcholine receptor concentration-response relationships in Xenopus oocytes. Neurosci Lett 256:163-166.

Quadri M, Garai S, Thakur GA, Stokes C, Gulsevin A, Horenstein NA, and Papke RL (2019) Macroscopic and microscopic activation of $\alpha 7$ nicotinic acetylcholine receptors by the structurally unrelated allosteric agonist-positive allosteric modulators (ago-PAMs) B-973B and GAT107. Mol Pharmacol 95:43-61.

Rozental R, Aracava Y, Scoble GT, Swanson KL, Wonnacott S, and Albuquerque EX (1989) Agonist recognition site of the peripheral acetylcholine receptor ion channel complex differentiates the enantiomers of nicotine. J Pharmacol Exp Ther 251: 395-404.

Spurny R, Debaveye S, Farinha A, Veys K, Vos AM, Gossas T, Atack J, Bertrand S, Bertrand D, Danielson UH, et al. (2015) Molecular blueprint of allosteric binding sites in a homologue of the agonist-binding domain of the $\alpha 7$ nicotinic acetylcholine receptor. Proc Natl Acad Sci USA 112:E2543-E2552.

Stokes C, Garai S, Kulkarni AR, Cantwell LN, Noviello CM, Hibbs RE, Horenstein NA, Abboud KA, Thakur GA, and Papke RL (2019) Heteromeric neuronal nicotinic acetylcholine receptors with mutant $\beta$ subunits acquire sensitivity to $\alpha 7$-selective positive allosteric modulators. J Pharmacol Exp Ther 370:252-268.

Thakur GA, Kulkarni AR, Deschamps JR, and Papke RL (2013) Expeditious synthesis, enantiomeric resolution, and enantiomer functional characterization of (4(4-bromophenyl)-3a,4,5,9b-tetrahydro-3H-cyclopenta[c]quinoline-8-sulfonamide (4BP-TQS): an allosteric agonist-positive allosteric modulator of $\alpha 7$ nicotinic acetylcholine receptors. J Med Chem 56:8943-8947.

Wang X, Daley C, Gakhar V, Lange H, Vardigan JD, Pearson M, Zhou X, Warren L, Miller CO, Belden M, et al. (2020) Pharmacological characterization of the novel and selective $\alpha 7$ nicotinic acetylcholine receptor-positive allosteric modulator BNC375. J Pharmacol Exp Ther 373:311-324.

Webster JC, Francis MM, Porter JK, Robinson G, Stokes C, Horenstein B, and Papke RL (1999) Antagonist activities of mecamylamine and nicotine show reciprocal dependence on beta subunit sequence in the second transmembrane domain. $\mathrm{Br}$ J Pharmacol 127:1337-1348.

Williams DK, Peng C, Kimbrell MR, and Papke RL (2012) Intrinsically low open probability of $\alpha 7$ nicotinic acetylcholine receptors can be overcome by positive allosteric modulation and serum factors leading to the generation of excitotoxic currents at physiological temperatures. Mol Pharmacol 82:746-759.

Williams DK, Wang J, and Papke RL (2011) Positive allosteric modulators as an approach to nicotinic acetylcholine receptor-targeted therapeutics: advantages and limitations. Biochem Pharmacol 82:915-930.

Young GT, Zwart R, Walker AS, Sher E, and Millar NS (2008) Potentiation of alpha7 nicotinic acetylcholine receptors via an allosteric transmembrane site. Proc Natl Acad Sci USA 105:14686-14691.

Zhou Y, Nelson ME, Kuryatov A, Choi C, Cooper J, and Lindstrom J (2003) Human alpha4beta2 acetylcholine receptors formed from linked subunits. J Neurosci $\mathbf{2 3}$ 9004-9015.

Address correspondence to: Roger L. Papke, Department of Pharmacology and Therapeutics, University of Florida, P.O. Box 100267, Gainesville, FL 32610-0267. E-mail: rlpapke@ufl.edu; orGanesh A. Thakur, Department of Pharmaceutical Sciences, School of Pharmacy, Bouvé College of Health Sciences, Northeastern University, Boston, MA 02115. E-mail: g.thakur@ northeastern.edu 